\title{
Escultura em madeira em Laranjeiras/SE: perspectivas do patrimônio material e imaterial no século XXI.
}

\section{Resumo:}

Janaina Cardoso de Mello*

O trabalho traça o panorama conceitual e prático do "patrimônio material" e "patrimônio imaterial", em suas intercessões, no contexto da cidade de Laranjeiras em Sergipe. A metodologia utiliza a entrevista gravada, semi-estruturada, com Demar (Ademar), escultor em madeira, cuja produção cria, expõe e comercializa no Centro de Artesanato, agraciado com o título de "patrimônio vivo" pela Prefeitura. Com a alta tecnologia, a Arqueologia Pública deve ir às comunidades, ouvir suas demandas para compartilhar de informações, registro e conservação do patrimônio cultural que congrega em si características de seu modus vivendi, valorizando a diversidade e a sobrevivência da arte. Como referência os trabalhos de Sandra Pelegrini, Pedro Paulo Funari, UNESCO, IPHAN e Ana Carla Reis.

Palavras-chave: Patrimônio Material; Patrimônio Imaterial; Escultura em Madeira; Laranjeiras/SE; Cultura.

\section{Abstract:}

The work trace the conceptual and practical view of "material assets" and "intangible heritage", in his intercession from context of the city of Orange in Sergipe. The methodology used the recorded interview, semi-structured, with Demar (Ademar), sculptor in wood, whose production creates, displays and sells at the Centro de Artesanato, awarded the title of "living heritage" by the municipal government. With high-tech developed, Public Archaeology should go to communities, hear their demands and get means of information sharing, registration and preservation of cultural heritage, which itself features of their modus vivendi, valuing diversity and survival of art. As reference the works of Sandra Pelegrini, Pedro Paulo Funari, UNESCO, IPHAN and Ana Carla Reis.

Keywords: Material Heritage; Intangible Heritage; Wood carving; Laranjeiras/SE; Culture. Resumen:

La búsqueda de trabajo traz el panorama conceptual y práctica de los "bienes materiales" y "patrimonio inmaterial", en su intercesión en el contexto de la ciudad de Laranjeiras en Sergipe. La metodología utiliza de la entrevista, semi-estructurada, con Demar (Ademar), escultor en madera, cuya producción crea, muestra y vende la artesanía centro, ha obtenido el

\footnotetext{
* Pós-Doutoranda em Estudos Culturais (PACC-UFRJ); Doutora em História Social (PPGHIS-UFRJ); Professora Adjunta do Bacharelado em Museologia da Universidade Federal de Sergipe (UFS) e Professora do Mestrado em História (PPGH) da Universidade Federal de Alagoas (UFAL); E-mail: janainamello@uol.com.br.
} 
título de "patrimonio vivo" por el gobierno municipal. Con la alta tecnología, Arqueología Pública debe ir a las comunidades para escuchar sus demandas y intercambiar información, registro y preservación del patrimonio cultural, que sí mismo características de su modus vivendi, valorando la diversidad y la supervivencia del arte. Como referencia los trabajos de Sandra Pelegrini, Pedro Paulo Funari, UNESCO, IPHAN y Ana Carla Reis.

Palabras clave: Patrimonios materiales; Patrimonio inmaterial; Talla de madera; Laranjeiras/SE; Cultura.

\section{Introdução}

O trabalho aqui apresentado tem como objetivo traçar o panorama da discussão conceitual e prática do que se convencionou denominar como "patrimônio material" e "patrimônio imaterial", em sua dicotomia distintiva e em suas intercessões possíveis, à partir do contexto da cidade de Laranjeiras em Sergipe.

O artigo percorre os caminhos sinuosos tanto das definições conceituais quanto das ruas de Laranjeiras com suas pedras centenárias, seus casarões oitocentistas e seus grupos de folguedos populares, buscando a aplicabilidade da convergência teórica à realidade concreta da cidade e de seus habitantes, para então adentrar ao universo da escultura em madeira própriamente onde o criador e suas criações são patrimonializados no século XXI.

É possível reunir os dois conceitos sem retirar deles suas especificidades, mas tornando-os suscetíveis à uma reflexão mais ampla e necessária para se pensar o futuro do patrimônio cultural arqueológico?

Para tentar responder à essa questão problema, utiliza-se como estudo de caso a entrevista realizada com Demar (Ademar), escultor em madeira de Laranjeiras, cuja produção cria, expõe e comercializa no Centro de Artesanato, tendo sido agraciado com o título de "patrimônio vivo" pela Prefeitura por seu ofício.

A entrevista foi gravada, perfazendo o total de 140 minutos, com perguntas semiestruturadas que abordavam a vida do escultor, sua arte, sua relação com a cidade e as políticas patrimoniais locais.

\section{Dos conceitos de cultura material à prática do imaterial.}

Discutir o patrimônio cultural no século XXI pressupõe refletir tanto sobre suas formas de produção quanto de conservação da cultura material para os estudos arqueológicos do porvir. Nesse sentido, imaterialidade e materialidade se fundem numa imbricada relação. Isto 
posto que durante muito tempo acostumou-se a tratar desses conceitos e práticas como ambiências separadas, sem contudo enfatizar os entrelaçamentos que as envolvem.

O Instituto do Patrimônio Histórico e Artístico Nacional (IPHAN) compreende como patrimônio material:

um conjunto de bens culturais classificados segundo sua natureza nos quatro Livros do Tombo: arqueológico, paisagístico e etnográfico; histórico; belas artes; e das artes aplicadas. Eles estão divididos em bens imóveis como os núcleos urbanos, sítios arqueológicos e paisagísticos e bens individuais; e móveis como coleções arqueológicas, acervos museológicos, documentais, bibliográficos, arquivísticos, videográficos, fotográficos e cinematográficos (IPHAN, 2015).

Material, tangível, físico, ou seja, aquilo que se pode ver, tocar, manter em suas estruturas de pedra e cal, de ferro e vidro, de madeira e etc. ensejando sua durabilidade, conservação e agregação de valor conforme distintos campos de saber acadêmico e a vontade da própria comunidade onde reside ou de onde provém o bem cultural.

Já o conceito de "patrimônio imaterial" foi definido no $2^{\circ}$ artigo do documento produzido na Convenção para Salvaguarda do Patrimônio Imaterial, realizada em Paris de 29 de setembro ao dia 17 de outubro de 2003, sob a chancela da Organização das Nações Unidas (UNESCO) como:

as práticas, representações, expressões, conhecimentos e técnicas - junto com os instrumentos, objetos, artefatos e lugares culturais que thes são associados - que as comunidades, os grupos e, em alguns casos, os indivíduos reconhecem como parte integrante de seu patrimônio cultural. Este patrimônio cultural imaterial, que se transmite de geração em geração, é constantemente recriado pelas comunidades e grupos em função de seu ambiente, de sua interação com a natureza e de sua história, gerando um sentimento de identidade e continuidade e contribuindo assim para promover o respeito à diversidade cultural e à criatividade humana (UNESCO, 2006:4).

A implementação do Registro de Bens Culturais de Natureza Imaterial normatizado pelo Decreto ํㅜ 3.551/2000 ampliou as ações de tombamento do patrimônio histórico nacional à partir de novos instrumentos de acautelamento dos bens intangíveis, à saber, os: Livro de registro dos saberes, Livro das formas de expressão, Livro das celebrações e Livro dos lugares. Estando contido nos dois primeiros livros os "conhecimentos e 'modos de fazer' enraizados no cotidiano das comunidades" (PELEGRINI, 2009: 29-30). 
A preocupação com o registro da memória coletiva ${ }^{1}$ e a salvaguarda do patrimônio cultural decorrem do reconhecimento de que: "as expressões culturais constituem um dos mais intensos exemplos da criatividade e da persistência das tradições das diversas etnias que se entrecruzaram e formaram a nação brasileira" (PELEGRINI; FUNARI, 2008: 82).

Embora tenha sido necessário esse demembramento conceitual do patrimônio cultural, ação que ainda suscita muita contestação no meio cultural e acadêmico, tinha-se como pressuposto descentralizar a gama de investimentos em edificações e conferir visibilidade e viabilidade de manutenção das tradições populares intangíveis que por muito tempo permaneceram como lutas solitárias nas comunidades, distantes do financiamento de políticas públicas.

Todavia, poucas pessoas - incluindo intelectuais e agentes culturais - têm refletido sobre uma dinâmica maior cuja premissa seja a de articular essas duas áreas, tendo em vista que, por exemplo, as ruas de pedra "pé-de-moleque" na cidade de Laranjeiras (Sergipe) enquanto registro material de uma época (o século XIX), contém ainda o trabalho de escravos que arduamente compuseram suas distribuição geométrica. Também os casarões oitocentistas (moradias, Trapiche, igrejas e atuais museus) da mesma cidade, tombados pelo Estado e depois pelo governo federal nas décadas de 1940 e respectivamente 1990, apoiados em sua restauração pelo Programa Monumenta (SILVA; NOGUEIRA, 2009: 44-51), foram erguidos pelo mesmo trabalho escravo que emanava das lavouras açucareiras da região do rio Cotinguiba. O trabalho, esse "modo de fazer" tão intangível mas que resulta em produtos materiais tão perceptíveis.

E por essas ruas de pedra pé-de-moleque, pela frente desses casarões, fazendo sombra nos azulejos que ainda subsistem, subindo as escadarias das igrejas transitam os grupos que conservam as tradições culturais brincantes de outrora: Cacumbi, Taieiras, Samba de Pareia, Chegança, São Gonçalo do Amarante, dentre outros (ALENCAR, 2003).

E tendo sua população em grande parte oriunda de negros, Laranjeiras é ainda uma cidade que conserva suas tradições religiosas de matriz africana representadas pelos vários terreiros, pelas denominações Nagô, Caboclo, Obá, Angola, Jeje, Ketu, ljexá (DANTAS, 1988). Há também, a celebração de São Benedito e Nossa Senhora do Rosário, em 06 de janeiro, quando a coração das rainhas das Taieiras é realizada na Igreja Católica (DANTAS, 1972).

\footnotetext{
${ }^{1}$ Partindo-se da premissa de que a memória coletiva é "uma corrente de pensamento contínuo, de uma continuidade que nada tem de artificial, pois não retém do passado senão o que está vivo ou é capaz de viver na consciência do grupo que a mantém" (HALBWACHS, 2006, p.102).
}

(C) Rev. Arqueologia Pública

\begin{tabular}{l|l|} 
Campinas, SP & v.9
\end{tabular}

No.(11)

p.167-178 suplemento

ISSN 2237-8294 
Assim, imaterialidade e materialidade se misturam, numa hibridez de sentidos e usos sociais, onde prédios e ruas justificam-se pela ocupação não apenas das necessidades urbanas cotidianas (moradia e serviços), mas especialmente pela presença de uma intensa diversidade cultural que the confere significado.

Por isso, para além de ser a dita "Atenas sergipana", Laranjeiras corporifica-se como uma terra de todos e para todos, de culturas africanas, lusitanas, indígenas (na representação do Lambe-sujo e Caboclinhos), com suas contribuições, suas tensões, conflitos e criações artíticas.

É em razão dessa apropriação da cultura material pela imaginação poética imaterial que tais lugares são verdadeiramente democratizados como lócus de todos e não somente de um determinado grupo social conforme hierarquias político-econômicas. Talvez seja esse processo que faça as culturas persistirem aos esquecimentos do tempo, às dificuldades do cotidiano e aos efeitos homogeneizantes da globalização tecnológica no século XXI.

Mas essa cidade, também contém outras experiências que conseguem transmutar-se em uma perfeita representação da união entre o imaterial (saber fazer) e o material (produto tangível) presente nas figuras do artesanato local da renda irlandesa e das esculturas em argila e madeira.

\section{Escultura em madeira: produto e produtor.}

A entrevista com o escultor Demar, como é conhecido, foi realizada pela manhã, no Centro de Artesanato na cidade de Laranjeiras em 05 de janeiro de 2015. Com 71 anos, moreno, com muita tenacidade e modos bem expansivos e agradáveis o artista é muito querido na cidade, no estado e fora dele.

Muito falante, o artesão falou sobre o gosto de sua clientela por variedade e enquanto cedia a entrevista gravada em MP3, produzia suas peças em madeira. Falou de sua preferência por esculpir peças inteiras, sem remendos. Relatou seu autodidatismo, sua impossibilidade de avançar nos estudos, sua curiosidade desde pequeno pelo ofício em madeira, sua busca pela melhoria das técnicas e das peças. Disse ele:

Tem o fator de gostar de fazer, tem o fator de fazer pra vender, tem o fator de fazer porque as pessoas apreciam...elogios não enche barriga, mas você tá sempre fazendo o que gosta e o que o povo passa a gostar.

(C) Rev. Arqueologia Pública Campinas, SP v.9 No.(11) p.167-178 suplemento ISSN 2237-8294 
Ele reclama de não ter um grande fluxo turístico na cidade, como no Rio de Janeiro, em São Paulo e Salvador, contudo, ressalta que há uma boa visitação do local o ano inteiro promovendo a comercialização do artesanato local, diferentemente de outros lugares em Sergipe mesmo quando os turistas só aparecem em grandes eventos culturais.

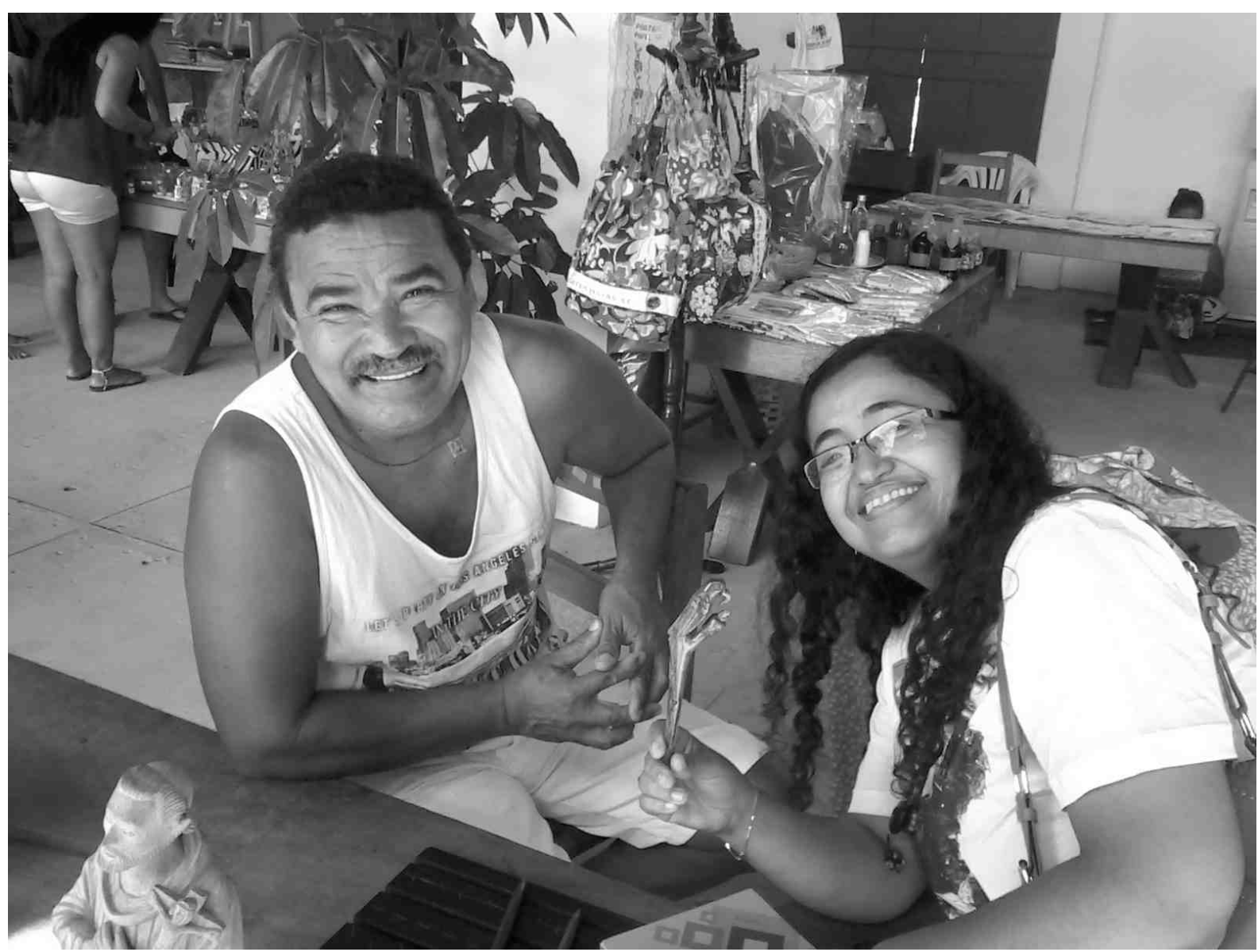

Imagens 1: $\mathrm{O}$ escultor durante a entrevista no Centro de Artesanato em Laranjeiras-SE. Fonte: Foto Hildênia Santos Oliveira, 2015.

Relatou que iniciou sua arte aos nove anos, mas ainda não sabia muito bem trabalhar nas peças, foi aprendendo, se cortando com gilete, com canivete com o qual sempre andava, mas sem perder a vontade de moldar os pedaços de madeiras em obras de sua imaginação ou lembrança.

Conta que uma de suas primeira peças foi uma cabeça de São Francisco em madeira para sua avó. Depois foi fazendo canoas, adquirindo maior domínio sobre o manuseio da

v.9

No.(11)

p.167-178 suplemento 
técnica, tendo a obstinação levado-o a viajar com sua arte para eventos de artesanato em São Paulo onde terminou por discursar.

A arte de Demar é assinada e diversificada, em madeira de cedro, mostrando tanto o seu perfil utilitário em peças pequenas (ímãs de geladeira, canetas) com menor preço na venda e maior saída no interesse da maioria dos visitantes (uma caneta custa entre $R \$ 15,00$ e $\mathrm{R} \$ 20,00)$ quanto sua arte como "Santeiro" com peças maiores, com elaborados detalhes e maior dificuldade no processo de entalhar um pedaço inteiro de madeira, dando-lhe forma e expressão (um São Jorge custa aproximadamente $R \$ 4.500,00$ ) cujo fluxo de comercialização normalmente se destina à encomendas.
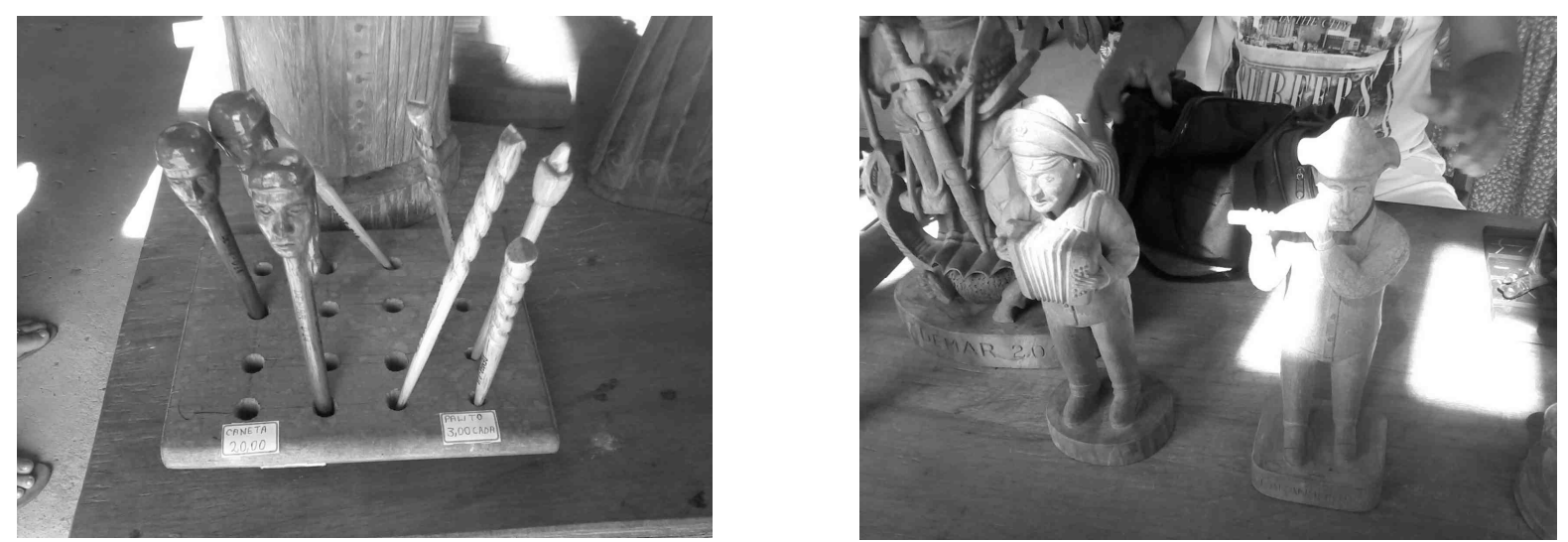

Imagens 2 e 3: A escultura em madeira de canetas, ornamento de cabelo feminino e da cultura popular do Nordeste (sanfoneiro e flautista de pífano)

Fonte: Fotos Janaina Mello, 2015.

Todavia, são as obras dedicadas à religiosidade católica que chamam mais a atenção pela arte-sacra figurativa cujos traços revelam em cada peça movimento, originalidade distinta e enriquecida pela experiência do artesão com o passar dos anos. A própria força da religiosidade católica na cidade, presente nas muitas igrejas e no Museu de Arte Sacra, emana nas opções estéticas do artista.

A cultura material, portanto, é repleta de intencionalidade; ela é concebida, materializada e utilizada dentro de determinadas sociedades. Por isso, ela pode ser lida para a compreensão do funcionamento das regras culturais. É importante destacar que existem inúmeras maneiras de analisar os vestígios materiais e refletir sobre suas intencionalidades e efeitos. A leitura sobre o universo material, entretanto, é crucial para a compreensão das regras culturais e sociais em que estamos inseridos (CARVALHO; FUNARI, 2009). 

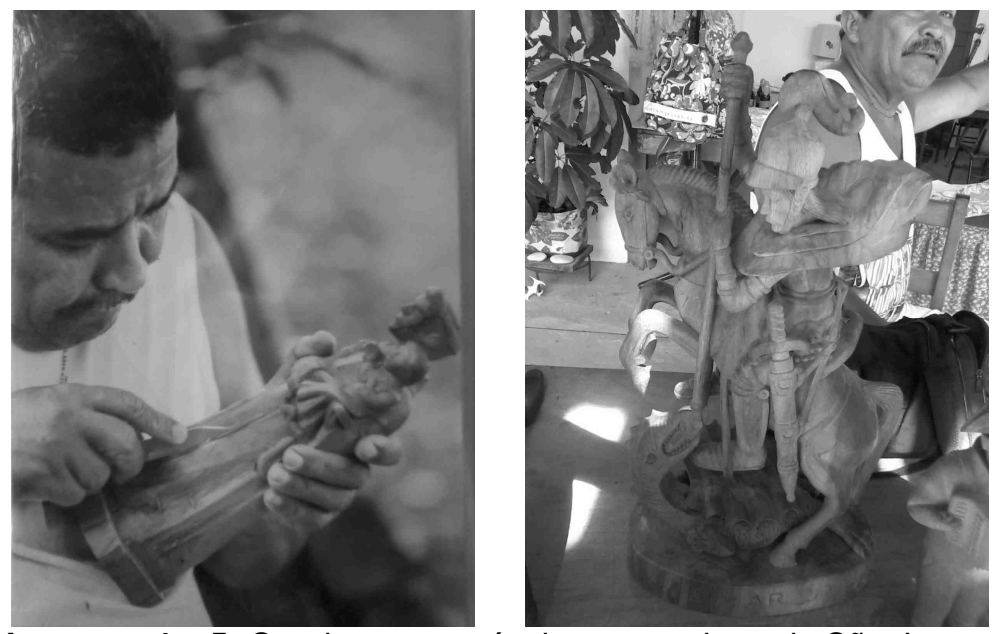

Imagens 4 e 5: O artista e sua técnica; a escultura de São Jorge Fonte: Fotos Acervo Demar e Janaina Mello, 2015.

No Brasil, principlamente na região Nordeste, existem exímios "Santeiros" destacandose: Chico Santeiro (Santo Antônio do Salto da Onça/RN), Luzia Dantas (Currais Novos/RN), Neném de Chicó (Jardim do Seridó/RN), Osmundo Teixeira (Itabuna/BA), Mestre Dezinho (Valença do Piauí/ PI), Mestre Expedito (Teresina/PI), Paquinha (Teresina/PI) dentre muitos outros, sendo a maioria deles autodidatas. Nesse ramo de artesanato encontra-se uma diversidade de formas, texturas, materiais, cores revelando de tendências mais delicadas e detalhistas à peças mais rústicas ou com relevos mais profundos. 


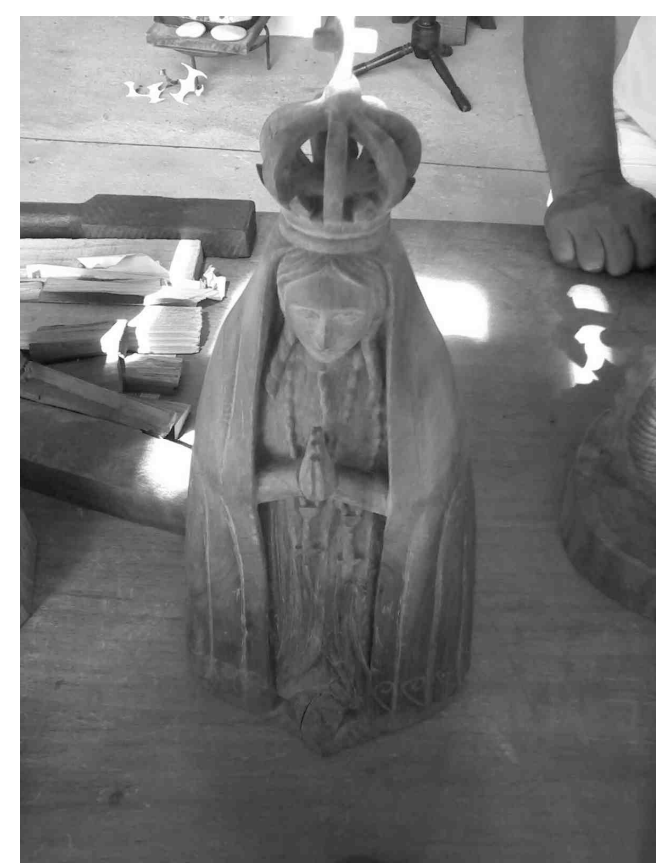

Imagem 6: Nossa Senhora

Fonte: Foto Janaina Mello, 2015.

Demar parte quase sempre de um desenho à partir do qual produz suas peças. Possui consigo o registro da maioria de suas peças em um álbum de fotografias impressas resultantes de máquinas analógicas. Sua preocupação com a conservação da memória de seus produtos coincide com o fato do artista ainda não possuir um catálogo oficial de suas esculturas, apesar de ter recebido o título e o benefício de Patrimônio Vivo de Laranjeiras/SE.

O Registro do Patrimônio Vivo é o reconhecimento da importância do saber tradicional e popular que os mestres e mestras transmitem de geração em geração. Contribui como um estímulo à preservação da cultura do Estado nas áreas de danças, folguedos, literatura oral e/ou escrita, gastronomia, música, teatro, artesanato, dentre outras. O título, personificado em um certificado entregue em cerimônia pública, traz ainda como benefício um valor mensal de incentivo vitalício configurado em um salário mínimo e meio.

No Brasil, o Maranhão (MA), Piauí (PI), Acre (AC), Espírito Santo (ES), Pernambuco $(\mathrm{PE})$, Minas Gerais (MG), Ceará (CE), Distrito Federal (DF), Bahia (BA), Alagoas (AL), Santa Catarina (SC), Paraíba (PB) são os Estados que possuem uma legislação específica relacionada ao patrimônio cultural imaterial (CAVALCANTI; FONSECA, 2008). No caso de Sergipe, a iniciativa do "Patrimônio Vivo" restringe-se à Prefeitura Municipal de Laranjeiras, 
não sendo uma ação do estado. Nota-se que dos 9 estados da região Nordeste, 7 seguem o compasso da salvaguarda do patrimônio, enquanto grandes Estados da região Sudeste como Rio de Janeiro (RJ) e São Paulo (SP) permanecem ausentes, guiando-se apenas pela Constituição Federal de 1988.

$O$ artista que se dedica ao entalhamento seja em madeira ou pedra, termina por prolongar as referências culturais de uma determinada comunidade ou localidade, expandindo sua visão para amplitudes maiores, uma vez que as peças são comercializadas em percursos nacionais e internacionais.

\section{Comercialização/conservação: o porvir das esculturas em madeira do século XXI.}

Um ponto que chama a atenção na contemporaneidade é o aumento das ações de conservação de bens culturais com a finalidade de preservá-los para as futuras gerações. Mas isso em si tem ensejado alguns problemas: 1. No campo do patrimônio arqueológico, a opção pelo trabalho com elementos da cultura material mais remota, tem levado a salvaguarda de peças oriundas de escavações e com isso pensa-se no passado, mas não necessáriamente no futuro das obras produzidas no tempo presente; 2 . As ações de conservação orientadas por políticas públicas selecionam obras que tenham reconhecimento histórico ou sejam validas por especialistas enquanto obra de arte, geralmente peças institucionais (igrejas, museus); 3. Peças destinadas à comercialização terminam entrando no circuito de aquisições particulares e enveredam por tantos caminhos sendo praticamente esquecidas pelos órgãos patrimoniais à exceção daquelas que são doadas à instituições culturais; 4 . A própria idéia de comercialização gera conflitos e tensões, uma vez que a produção de réplicas (por mais que cada uma apresente sua originalidade e distinções muito particulares por serem resultado de um trabalho manual e não industrial) termina por ser desvalorizada enquanto arte.

Entretanto, para além das funcionalidades próprias de cada objeto, as demandas do sistema capitalista terminam por incidir na produção artesanal, fazendo com que a própria concepção artística ganhe valor de mercado não apenas pelo uso prático, mas fundamentalmente pela apropriação cultural e identitária das peças.

Restará à Arqueologia no futuro o resgate dessas obras e sua posterior ação interventiva na restauração de peças derioradas? Haverá algum modo de trabalhar com os artesãos, a comunidade, museus, escolas, órgãos governamentais, instituições de fomento e 
de salvaguarda patrimonial na conscientização do valor do produtor e de seus produtos? Pensar o patrimônio cultural no século XXI, principalmente proveniente do artesanato em comunidades interioranas pressupõe pensar na sustentabilidade desses escultores para a continuidade do "saber-fazer".

A articulação cultura/comércio não é uma novidade, mas, é recente seu enquadramento no quadro da "Economia da Cultura", aqui entendida como:

o aprendizado e o instrumental da lógica e das relações econômicas - da visão de fluxos e trocas; das relações entre criação, produção, distribuição e demanda; das diferenças entre valor e preço; do reconhecimento do capital humano; dos mecanismos mais variados de incentivos, subsídios, fomento, intervenção e regulação; e de muito mais - em favor da política pública não só de cultura, como de desenvolvimento (REIS, 2009: 25).

Em tempos de alta tecnologia, a Arqueologia Pública deve ir às comunidades, ouvir suas demandas e busacar meios de compartilhamento de informações, registro e conservação do patrimônio cultural que congrega em si caracterísitcas de seu modus vivendi, valorizando a diversidade e a sobrevivência da arte.

Esses saberes com os quais a AP trabalha devem ser construídos de forma cooperativa e no sentido de fornecer instrumentos para que todos os envolvidos em um determinado projeto possam elaborar questionamentos e conclusões a respeito dos temas debatidos. Neste sentido, os diálogos, as críticas e as reflexões acerca da cultura material, entre os arqueólogos e os não arqueólogos, são as maiores responsabilidades da AP. (CARVALHO; FUNARI, 2008).

Como disse Demar: "Elogio não enche barriga", por isso uma Economia da Cultura que articule a questão patrimonial em torno das peças comercializadas, oficinas de conservação das peças para compradores, poderá personificar o futuro da cultura material em sua relação com a cultura imaterial, bem como o próprio futuro da Arqueologia no país.

\section{Referências Bibliográficas}

ALENCAR, A. D. F. Danças e Folguedos. Iniciação ao Folclore Sergipano. Aracaju: Edição do Autor, 2003.

CARVALHO, A. V.; FUNARI, P. P. As possibilidades da Arqueologia Pública. história e-história (2009). Disponível em: http://www.historiaehistoria.com.br/materia.cfm?tb=arqueologia\&id=31, Acesso em: 15/02/2015.

DANTAS, B. G. A Taieira de Sergipe. Petrópolis: Vozes, 1972. 
DANTAS, B. G. Vovó Nagô e papai branco: usos e abusos da África no Brasil. Rio de Janeiro: Graal, 1988.

IPHAN. Patrimônio Material. Disponível em: http://portal.jphan.gov.br/portal/montarPaginaSecao.do?id=12297\&retorno=paginalphan, Acesso em: 15/02/2015.

HALBWACHS, M. A Memória Coletiva. São Paulo: Centauro, 2006, p.102.

PELEGRINI, S. C. A. Patrimônio cultural: consciência e preservação. São Paulo: Brasiliense, 2009.

PELEGRINI, S. C. A.; FUNARI, P. P. O que é Patrimônio Cultural imaterial. Col. Primeiros Passos, 331, São Paulo: Brasiliense, 2008.

REIS, A. C. F. Economia da Cultura e Desenvolvimento. Estratégias nacionais e panorama global In: REIS, Ana Carla Fonseca; MARCO, Kátia (orgs.), Economia da Cultura. Idéias e vivências, Rio de Janeiro, Publit, 2009.

SILVA, E. D.; NOGUEIRA, A. D. Lançando um olhar sobre o patrimônio arquitetônico de Laranjeiras. In: NUNES, V. M.M.; NOGUEIRA, A. D. (Orgs.) O despertar do conhecimento na colina azulada: a universidade Federal de Sergipe em Laranjeiras. São Cristóvão: EDUFS, 2009. p.35-98.

UNESCO. Convenção para a salvaguarda do Patrimônio Cultural Imaterial, Brasília, Ministério das Relações Exteriores, 2006

\begin{tabular}{l|l} 
v.9 & No.(11)
\end{tabular}

